
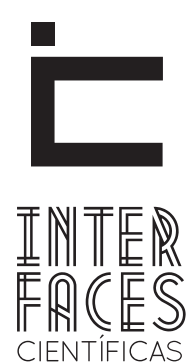

HUMANAS E SOCIAIS

ISSN IMPRESSO 2316-3348

E-ISSN 2316-3801

\title{
"ARQUIVAR A PRÓPRIA VIDA": O ACERVO PESSOAL JOSUÉ DE CASTRO COMO INSTRUMENTO PARA A PESQUISA HISTÓRICA.
}

"ARCHIVE TO OWN LIFE": THE COLLECTION PERSONAL INSTRUMENT AS JOSUÉ DE CASTRO FOR HISTORICAL RESEARCH “ARCHIVAR LA PROPIA VIDA": ACERVO PERSONAL DE JOSUÉ DE CASTRO COMO INSTRUMENTO PARA LA INVESTIGACIÓN HISTÓRICA

Helder Remigio de Amorim ${ }^{1}$

\section{RESUMO}

Este trabalho discute as problemáticas que envolvem a pesquisa histórica em um acervo pessoal, e tem como centro das discussões o arquivo pessoal Josué de Castro, salvaguardado pela Fundação Joaquim Nabuco. Os usos, a composição, os processos de institucionalização do acervo e a intenção de preservação da memória das atividades de um intelectual importante do pensamento social brasileiro são problematizados neste artigo. Nesse sentido, os debates em torno dos arquivos e dos acervos pessoais são fundamentais para que o historiador reúna rastros, fragmentos, pedaços do passado e por meio das questões do presente realize a operação historiográfica.

\section{PALAVRAS-CHAVE}

Arquivo Pessoal. História. Josué de Castro. 


\section{ABSTRACT}

This paper discusses the issues involving historical research on a personal collection, and is the center of discussions the personal file Josué de Castro, safeguarded by Joaquim Nabuco Foundation. The uses, composition, collection of institutionalization processes and the intention of preserving the memory of the activities of an important intellectual of the Brazilian social thought are problematized in this article. In this sense, the debates around the archives and personal collections are essential to the historian gather traces, fragments, pieces of the past and through the present issues perform the historiographical operation.

\section{KEYWORDS}

Personal archive. History. Josué de Castro

\section{RESUMEN}

Este documento analiza las cuestiones relacionadas con la investigación histórica en una colección personal, y el centro de las discusiones es el acervo personal Josué de Castro, salvaguardado por la Fundación Joaquim Nabuco. Los usos, la composición, los procesos de institucionalización del archivo y la intención de preservar la memoria de las actividades de un importante intelectual del pensamiento social brasileño se problematizan en este artículo. En este sentido, los debates en torno a los archivos y colecciones personales son esenciales para que el historiador reúna huellas, fragmentos y trozos del pasado y, por medio de las presentes cuestiones, realizar la operación historiográfica.

\section{PALABRAS CLAVE}

Acervo Personal. Historia. Josué de Castro 


\section{INTRODUÇÃ̃O}

O presente artigo versa sobre uma experiência de pesquisa que está sendo desenvolvida na Universidade Federal de Pernambuco para a tese de doutorado em História deste pesquisador, no Arquivo Pessoal Josué de Castro, salvaguardado pela Fundação Joaquim Nabuco ${ }^{1}$. A temática central da tese é estudar a trajetória política e intelectual de Josué de Castro entre as décadas de 1930 e 1970. Nesse sentido, para que as intenções deste trabalho sejam plausíveis, se faz necessário conhecer algumas especificidades da trajetória em questão.

Josué Apolônio de Castro, nasceu em 5 de setembro de 1908 na cidade do Recife, faleceu em 1973 em Paris, quando esteve exilado após o golpe civil-militar de 1964. A sua produção intelectual esteve aliada aos cargos públicos que ocupou como médico, professor universitário, presidente do Conselho Consultivo da $\mathrm{FAO}^{2}$, deputado federal, embaixador, e presidente do Centro Internacional de Desenvolvimento em Paris (CID). Em relação à dimensão política e social do seu pensamento, desenvolveu ações para desnaturalizar a fome como atributo dos pobres e resultado das condições climáticas e de solo. Destacam-se no âmbito dos debates acerca da sociedade brasileira, os estudos de Josué de Castro sobre as condições alimentares da população e as análises referentes à estrutura agrária do país, para desenvolver esses temas se situou academicamente no campo de saber da geografia.

A sua obra foi traduzida em 25 idiomas, ganhou repercussão internacional principalmente quando publicou Geografia da Fome (1946) e Geopolítica da Fome (1951) livros que circularam com evidência tanto nos Estados Unidos da América como na União Soviética em tempos de Guerra Fria. No início da década de 1960, estima-se que sua obra havia vendido mais

\footnotetext{
1 A Fundação Joaquim Nabuco é um órgão do governo federal com sede em Recife-PE, ligada ao Ministério da Educação, fundada em 1947 por Gilberto Freyre, tem como missão atender a demandas e necessidades relacionadas a educação e cultura, compreendidas de forma interdependente, com vistas ao desenvolvimento justo e sustentável da sociedade brasileira 2 Organização das Nações Unidas para Alimentação e Agricultura com sede em Roma-Itália.
}

de 400.000 exemplares em todo mundo. Assim sendo, suas ideias estiveram voltadas desde a década de 1930 para a compreensão do fenômeno da fome que considerava ser fruto da exploração do homem pelo homem.

Durante a década de 1950, Josué de Castro foi deputado federal pelo Partido Trabalhista Brasileiro (PTB) de Pernambuco por duas legislaturas. Na sua atuação enquanto deputado defendeu a criação de uma reserva de alimentos no Brasil para os momentos de crise, a desapropriação de terras por interesse social, além de um plano nacional de alimentação e de merenda escolar. Destaca-se ainda a preocupação com a reforma agrária e a aproximação com os movimentos de trabalhadores rurais, especialmente com as Ligas Camponesas. Josué de Castro participou dos debates que criaram a Superintendência para o Desenvolvimento do Nordeste (SUDENE), e também das articulações para criação da Universidade de Brasília.

Em 1962, Josué de Castro renunciou ao mandato de deputado federal por ter sido nomeado, pelo então presidente João Goulart embaixador do Brasil para assuntos ligados a Organização das Nações Unidas (ONU) em Genebra. No entanto, foi destituído do cargo com o golpe civil-militar de 1964. Assim, como muitos intelectuais e políticos, Josué de Castro teve seus direitos políticos cassados. Naquela ocasião, vários países the ofereceram asilo político, mas escolheu a França para viver - onde teve destacada atuação intelectual como professor, escritor e articulista até os últimos dias de vida. Após apresentar minimamente alguns aspectos dessa trajetória, convido o leitor para adentrar no universo do Arquivo Pessoal de Josué de Castro.

\section{ARQUIVO OU “UM PAINEL COM MILHARES DE LÂMPADAS"}

0 que compreendemos sobre o significado da palavra arquivo? Do latim archivu, do grego arkheîon, tem como significado primeiro: "Casa ou móvel onde se conservam ou guardam documentos escritos”. Significa também "Repositório ou coleção de qualquer espécie de documentos ou outros materiais, como ma- 
nuscritos, fotografias, correspondências, importantes para as instituições civis ou governamentais, ou de valor histórico" (HOUAISS, 2001, p. 20). Essas duas definições nos permitem pensar alguns dos estatutos do arquivo. Primeiramente a noção do que é um documento, já que os arquivos são formados por um conjunto de documentos, de registros e de fundos. Posteriormente, a idéia de que o arquivo também é um repositório que tem por finalidade a conservação e a preservação.

Os arquivos constituem um fundo documental, comumente localizado em uma determinada instituição. É necessário ouvir Paul Ricouer (2007, p. 177): “Mas o arquivo não é apenas um lugar físico, espacial, é também um lugar social". No arquivo o historiador reúne rastros, fragmentos, pedaços do passado inspirado pelas questões do presente para realizar a operação historiográfica que significa essencialmente:

Encarar a história como uma operação será tentar, de maneira necessariamente limitada, compreendê-la como a relação entre um lugar (um recrutamento, um meio, uma profissão etc.), procedimentos de análise (uma disciplina) e a construção de um texto (uma literatura). (CERTEAU, 2007, p. 66).

0 arquivo é fundamental nessa operação, bem como complexo em sua materialidade, principalmente quando se dimensiona as diversas temporalidades e regimes de historicidade que habitam os documentos.

É dessa prática complexa permeada por regras e estatutos que o historiador se debruça sobre o mundo dos arquivos em busca de questões que norteiem as pesquisas. A produção da escrita apesar de se destinar sobre um olhar ao passado, é pensada de forma ambivalente para dar lugar a um futuro. Mas o arquivo se constitui um gesto primevo onde a emoção e o sentimento em torno dos documentos comumente fascinam o historiador. Essa simpatia natural pelo arquivo e pelos documentos deve ser pensada a partir do exercício da problematização sobre a constituição desses acervos, dos regimes de produção dos documentos, bem como da política institucional que os norteiam (FARGE, 2009, p. 73).
Josué de Castro deixou inúmeros registros das suas atividades de produção intelectual, de homem público e da vida pessoal. São muitos os fragmentos documentais que se estendem temporalmente dos primeiros anos do curso de Medicina iniciado na Bahia na década de 1920 até a repercussão da sua morte em Paris, 1973. Em uma tentativa de desnaturalizar a ideia de essência do personagem em questão, por meio de uma perspectiva de sujeito atrelada a multiplicidade, traçaremos o percurso em torno da construção de um arquivo pessoal que muito tem contribuído para produzir novas e velhas imagens de Josué de Castro.

Um arquivo pessoal é compreendido como um lugar de produção, e um dispositivo detentor de uma ação estratégica atrelada às relações de poder. Nesse sentido, um arquivo pessoal possui peculiaridades distintas em relação a um arquivo eminentemente institucional, principalmente nos processos de classificação e seleção do que deve ou não deve ser preservado.

Os arquivos pessoais, todavia, em geral trazem a marca de um processo de acumulação pautado por subjetividades individuais, expressas na seleção dos documentos a serem preservados, bem como em sucessivas avaliações, descartes e ordenamentos a que os conjuntos podem ser submetidos. (HEYMANN, 2012, p. 179).

0 ato de guardar, reunir, preservar informações pessoais e profissionais é próprio de uma sociedade que compreende a efemeridade da vida e demonstra a percepção de que, preservando a memória se lança para o futuro a possibilidade de continuar sendo lembrada. 0 arquivo pessoal Josué de Castro é tratado em sua dimensão histórica e significado na construção da memória, considerando que: "Arquivar a própria vida é por-se no espelho, é contrapor à imagem social a imagem íntima de si próprio, e nesse sentido o arquivamento do eu é uma prática de construção de si mesmo e de resistência" (ARTIĖRES, 1998, p. 11). Analisaremos, posteriormente, os processos de institucionalização do acervo, as suas infindáveis possibilidades de pesquisa, e os temas que elegemos como percursos para a tessitura dessa escrita. 


\section{UMA BREVE HISTÓRIA DO PROCESO DE INSTITUCIONALIZAÇÃO DO ACERVO}

Josué de Castro e seus familiares sempre se preocuparam em guardar documentos das atividades profissionais e pessoais. Esse arquivo pessoal possui cerca de 101 mil documentos. A maioria da documentação foi organizada e catalogada inicialmente por Glauce de Castro, sua esposa ${ }^{3}$, porém contou também com o acompanhamento e participação de Josué de Castro que demonstrava interesse pela atividade de guardar e preservar sua própria memória. A constituição desse arquivo pessoal ainda contou com colaborações de amigos, jornalistas que enviavam recortes de jornais, cartas, relatórios, livros e que, ao longo dos anos, foram compondo o acervo.

A história do processo de institucionalização desse acervo pessoal remete ao início do processo de redemocratização do Brasil, em 1979, quando um grupo de intelectuais fundou em Recife o Centro de Estudos e Pesquisas Josué de Castro. A ideia inicial era criar um ambiente de pesquisa que envolvesse temáticas ligadas à superação, e a investigação das causas da fome e da pobreza, relacionada aos direitos de cidadania.

O Centro de Estudos e Pesquisas Josué de Castro é uma entidade de direito privado sem fins lucrativos, que tem por objetivo contribuir para a construção e fortalecimento da democracia e da cidadania na perspectiva do acesso aos direitos humanos, através da pesquisa e da intervenção social. Foi fundado em 1979 por pesquisadores pernambucanos, alguns ainda no exílio e vinculados a diferentes Universidades, todos compartilhando do mesmo ideal de contribuir para a retomada da democracia em nosso país. A escolha do nome foi motivada pela identidade intelectual e humana com Josué de Castro, especialmente a independência, espírito crítico e compromisso com o processo de conhecimento e transformação da realidade. Trata-se de uma homenagem ao grande humanista pernambucano que se dedicou à luta contra as causas que originam a fome e a pobreza no mundo. (MELO; NEVES, 2007, p. 95).

3 A senhora Glauce do Rego de Castro sempre se preocupou em arquivar os registros das atividades de Josué de Castro, foi também uma companheira de viagens e leitora da sua produção intelectual.
Atividades acadêmicas, eventos, seminários, oficinas e parcerias institucionais fizeram do Centro Josué de Castro uma referência nacional em publicações e políticas públicas de cunho social. Essas atividades contribuíram para que em 1987, a família Castro realizasse a doação ao Centro de grande parte do acervo documental e pessoal do intelectual ${ }^{4}$. Além das contribuições já mencionadas a constituição material do acervo se deu em grande parte no Rio de Janeiro, cidade na qual Josué residiu a maior parte de sua vida, onde lecionou, clinicou e fez política. Porém outra parte do acervo foi composta em Paris onde viveu no exílio e desempenhou atividades acadêmicas na Universidade de Sorbonne e Vincennes e, ainda, presidiu o Centro Internacional para o Desenvolvimento ${ }^{5}$.

Durante o período da redemocratização nos anos 1980, o arquivo pessoal Josué de Castro passou pelo primeiro processo de institucionalização. Essa mudança não foi meramente geográfica, mas significou uma modificação de estatuto que alterou os sentidos atribuídos ao conjunto documental. Um arquivo quando se institucionaliza, apesar de não passar por reclassificações, restaurações e processos de higienização, deixa o âmbito da esfera privada e familiar e passa a habitar a dimensão pública no que concerne à pesquisa e consulta do acervo.

No entanto, no início dos anos 2000, o Centro Josué de Castro passou por dificuldades financeiras e estruturais que incidiram diretamente nos projetos que envolviam a catalogação e preservação do acervo documental em questão. Em 2010, os sócios dessa entidade de direito privado decidiram entrar em negociação com a Fundação Joaquim Nabuco para que o acervo fosse doado para uma entidade que tivesse recursos para preservação da documentação que estava paulatinamente se degradando.

Um novo trâmite burocrático foi realizado entre a família e a Fundação Joaquim Nabuco para transferência do acervo. 0 processo de higienização foi fina-

\footnotetext{
4 Nesse processo destacou-se o Professor Denis Bernardes (in memorian), profundo conhecedor do acervo e da obra de Josué de Castro.

5 Organização não-governamental que tinha como finalidade central encorajar, estimular, empreender e realizar pesquisas, estudos, projetos e outras iniciativas capazes de promover e acelerar o desenvolvimento econômico autêntico e equilibrado do mundo.
} 
lizado em 2013 nos documentos manuscritos e fotografias. Estes já estão disponíveis para a sociedade, porém os livros da biblioteca de Josué de Castro composta por cerca de 9 mil volumes, em grande parte ainda aguardam processos de higienização e restauro.

É importante ressaltar que a transferência do acervo para a Fundação Joaquim Nabuco instaurou acesso público aos documentos, bem como acondicionamento adequado. Nesse sentido, uma série de pesquisas de mestrandos e doutorandos de diversos campos do saber está sendo realizada desde a disponibilização do acervo. Uma releitura das pesquisas anteriores e novas formas de análise dos temas que envolvem Josué de Castro estão em curso. Contudo, os processos de institucionalização devem tentar preservar o histórico, a lógica que prescindiu a organização do autor, levando em conta que:

\begin{abstract}
Uma característica essencial dos arquivos pessoais reside na preponderância do valor informativo de seus documentos, isto é, seu valor de uso para fins históricos. 0 valor de prova legal, característica essencial dos documentos públicos, perde esse sentido estrito para os papéis privados. Mas se alargarmos esse conceito, também podemos dizer que, na organicidade de um arquivo pessoal, na maneira como os documentos foram organizados e mantidos em seu local de origem, é que reside seu valor de prova. Essa maneira atesta, por exemplo, as intenções e os sentidos emprestados pelo titular do arquivo relativos ao uso dos documentos acumulados. (FRAIZ, 1998, p. 67).
\end{abstract}

A preocupação de Josué de Castro com a preservação da sua memória é nítida no decorrer da sua trajetória. As demandas sociais do tempo vivido surgem como rastros importantes para compreender as prioridades e os critérios do que era de interesse guardar e preservar.

\section{A MULTIPLICIDADE DO ARQUIVO PESSOAL JOSUÉ DE CASTRO}

O acervo pessoal de Josué de Castro é formado por documentos variados como fotografias, correspondências, discursos, diplomas, recortes de jornais, panfle- tos, atas de reuniões, agendas, registros que se referem a obra do autor, a trajetória de homem público, a atividade docente, ao exílio, bem como as atividades de militante de diversas organizações de combate a fome. Nesse acervo, as correspondências ativas e passivas possibilitam investigar as relações políticas e intelectuais de Josué de Castro. A vasta correspondência com personalidades do meio cultural e intelectual, familiares, amigos tem permitido identificar a pluralidade da sua imagem, analisando determinados acontecimentos por meio de múltiplas perspectivas.

Outro importante conjunto documental do acervo é constituído por parte da sua produção intelectual, artigos em versões originais, correções de textos, anotações, rabiscos. Em outras palavras, contendo "evidência histórica que precisa ser conservada com carinho e técnica” (PALLARES-BURKE, 2005, p. 34), pois apontam traços e reflexões do próprio autor. Sobre a importância do arquivo pessoal Josué de Castro comentou o sociólogo Denis Bernardes:

\begin{abstract}
São vários, são vários os “Josués”. É a grande riqueza desse acervo. É o Josué do início da sua carreira, como estudante, já voltado para a literatura, no campo do cinema, o comentador de Freud aos 17 anos - algo extremamente interessante - o médico e em seguida, sem que isso seja uma divisão, o pesquisador da nutrição, o político. Coroando tudo isso o Josué, o homem universal, o brasileiro universal, é o que nós encontramos nessa documentação, na sua correspondência, na sua preocupação, no seu arquivo de recortes de jornais. Parte da história, não só do homem Josué, mas parte da história brasileira está nesse arquivo. (TENDLER, 1995).
\end{abstract}

A partir desse trecho de uma entrevista para o documentário Josué de Castro: Cidadão do Mundo, Denis Bernardes, aponta duas dimensões importantes do acervo. A primeira delas é a dimensão histórica, lembrada na relação entre o indivíduo e o tempo vivido. Os acontecimentos que marcaram o século $X X$ foram preponderantes para constituir o sujeito Josué de Castro. As redes intelectuais e políticas, as experiências em diversos campos do saber surgem como um caleidoscópio e apontam tanto para o acervo como para a dimensão múltipla do personagem em questão. 
Afinal cada um de nós deve ser compreendido como "um lócus no qual uma incoerente e frequentemente contraditória pluralidade de determinações relacionais que interagem entre si" (CERTEAU, 2008, p. 38).

No entanto, a riqueza documental, as inúmeras possibilidades de pesquisas, as muitas histórias a serem contadas, não podem de modo algum se transformarem em "um culto ao arquivo". O historiador necessita buscar estratégias para não ceder, pois a "obediência cega à positividade do arquivo, a seu poder absoluto, leva tanto a uma impossibilidade da história quanto a recusa do arquivo" (ROUDINESCO, 2009, p. 6). Ao mesmo tempo analisar o arquivo como um dispositivo que possibilita a criação de uma autoimagem de Josué de Castro se faz latente, onde a intencionalidade do titular em demarcar a multiplicidade de sua própria imagem.

Desse modo, é importante empregar a crítica documental e arquivística para fugir de uma visão cristalizada da história. Até porque o arquivo não é constituído de uma massa documental estática, pois tem no registro do passado a sua principal referência temporal (BIRMAN, 2008). A necessidade de cruzamento documental com outros acervos de pesquisa foi um dos caminhos trilhados nessa pesquisa (SIQUEIRA, 2015).

\section{ARQUIVO COMO UMA ESCRITA DE SI}

Trabalhar com as fontes documentais desse acervo também requer uma aproximação com temáticas ligadas a produção de identidades, bem como das relações entre memória individual e social. 0 processo de acumulação desses documentos também deve ser compreendido como uma escrita de si "que integra um conjunto de modalidades do que se convencionou chamar produção de si no mundo moderno ocidental” (GOMES, 2004, p. 10). Essa denominação pode, também, ser bem entendida a partir da relação que se construiu entre o indivíduo moderno e os seus documentos, não no sentido do diário, do íntimo, mas na perspectiva do processo de produção intelectual, dos pensamentos, das reflexões, bem como da rede de relações cultivadas.
Os escritos, as reportagens de jornais, as correspondências entre outros documentos produzem um universo em torno do autor, na perspectiva da produção de imagens de um intelectual ligado as causas sociais no Brasil e no mundo. Esse processo de produção de imagens também está relacionado com a mobilização de discursos e práticas

Um detalhe importante sobre a composição desse acervo é que a documentação está mais concentrada entre as décadas de 1940 e 1970, período em que Josué de Castro se torna um escritor de obras que circulam internacionalmente, estabelece redes intelectuais em diversos países, e passa a acumular um maior número de documentos. A necessidade de cruzamento de informações com outros acervos documentais, inerente a pesquisa acadêmica, também se faz obrigatória no que concerne ao período em que Josué de Castro se formou em medicina, no Rio de Janeiro em 1929, perpassando por toda a década de 1930, até a publicação de Geografia da Fome em 1946. Principalmente pela fragmentação e até mesmo ausência de documentos desses momentos históricos.

Esse processo de autoconstrução de Josué de Castro foi se constituindo em diversos campos do saber, bem como na escolha dos objetos de pesquisa. Um dos temas que acompanhou praticamente toda a sua trajetória foi a problematização da fome, tema ligado econômico e socialmente ao Pós-Guerra, principalmente no momento de reconstrução da Europa. Paulatinamente seus escritos sobre a fome passaram a fazer parte dos seus interesses de produção intelectual.

Por fim, é importante mencionar que uma parte da documentação do acervo pessoal Josué de Castro ainda está sob guarda de uma das suas filhas, Ana Maria Castro, no Rio de Janeiro. Essa parte do acervo é composta por correspondências, fragmentos de diários e inúmeras fotografias. Outra parte do acervo composta por medalhas, diplomas e títulos honoríficos está sob guarda de Josué Fernando de Castro também filho do intelectual. A partir do momento que outros conjuntos documentais se somarem ao acervo, novas possibilidades de pesquisas e novos mundos serão paulatinamente revelados. 


\section{REFERÊNCIAS}

ARTIÈRES, Philippe. Arquivar a própria vida. Estudos

históricos. Rio de Janeiro, v.11, n.21, 1998.

BIRMAN, Joel. Arquivo e mal de arquivo: uma leitura de Derrida sobre Freud. Natureza Humana, v.10, n.1, p.105-128, jan.-jun. 2008.

BOLLE, Willi. Um painel com milhares de lâmpadas. Metrópole \& Megacidade (Posfácio à edição brasileira). In: BENJAMIN, Walter. Passagens. Organização da edição brasileira Willi Bolle; colaboração na organização da edição brasileira Olgária Chain F. Matos. Belo Horizonte: UFMG; São Paulo: Imprensa Oficial do Estado de São Paulo, 2006.

CASTRO, Josué de. Geografia da fome. A fome no Brasil. Rio de Janeiro: Cruzeiro, 1946.

CERTEAU, Michel de. A escrita da história. Rio de Janeiro: Forense Universitária, 2007.

CERTEAU, Michel de. A invenção do cotidiano: arte de fazer. Petrópolis: Vozes, 2008.

DOSSE, François. 0 desafio biográfico. Escrever uma vida. São Paulo: Universidade de São Paulo, 2009.

FARGE, Arlette. $\mathbf{O}$ sabor do arquivo. São Paulo: Universidade de São Paulo, 2009.

FRAIZ, Priscila. A Dimensão autobiográfica dos arquivos pessoais: 0 arquivo de Gustavo Capanema.

Estudos Históricos, v.11, n.21, Rio de Janeiro, 1998.
FOUCAULT, Michel. Microfísica do poder. Rio de Janeiro: Graal, 2011.

GOMES, Angela de Castro (Org.). Escrita de si, escrita da história. Rio de Janeiro: FGV, 2004.

HEYMANN, Lúcia Quillet. 0 lugar do arquivo: a construção do legado de Darcy Ribeiro. Rio de Janeiro: Contracapa, 2012.

HOUAISS, Antônio. Dicionário Houaiss da língua portuguesa. Rio de Janeiro: Objetiva, 2001.

MELO, Marcelo Mário de; NEVES, Teresa Cristina Wanderley (Org.). Josué de Castro. Série Perfis Parlamentares, n.52. Brasília: Câmara dos Deputados, Coordenação de Publicações, 2007.

PALLARES-BURKE, Maria Lúcia Garcia. Gilberto Freyre: um vitoriano nos trópicos. São Paulo: UNESP, 2005.

RICOEUR, Paul. A memória, a história e o esquecimento. Campinas, SP: UNICAMP, 2007.

ROUDINESCO, Elisabeth. A análise e o arquivo. Rio de Janeiro: Jorge Zahar, 2006.

SIQUEIRA, Antônio Jorge de. Discussão sobre o livro-texto “Mal de Arquivo”. Palestra. PósGraduação em História - CFCH/UFPE, 2015

TENDLER, Silvio. Josué de Castro: Cidadão do Mundo. 55”. Rio de Janeiro, UERJ Vídeo, Bárbara Produções, 1995.

SILVA, Tânia Elias Magno (Org.). Josué de Castro. Rio de Janeiro: Fundação Miguel de Cervantes, 2012. 
Recebido em: 11 de agosto de 2016

Avaliado em: 12 de março de 2017

Aceito em : 16 de março de 2017
1 Historiador; Mestre em História pela Universidade Federal Rural de Pernambuco - UFRPE; Doutorando em História na linha de pesquisa Cultura e Memória pela Universidade Federal de Pernambuco. E-mail: hra1901@hotmail.com 
